\title{
The Production and Reproduction of Kinship in Charitable Children's Institutions in Uasin Gishu County, Kenya
}

\author{
Allison Gayapersad ${ }^{4}$. Caroline Ombok ${ }^{3} \cdot$ Allan Kamanda $^{6} \cdot$ Carren Tarus $^{3}$. \\ David Ayuku ${ }^{5}$ Paula Braitstein ${ }^{1,2,3}$
}

Published online: 3 May 2019

(c) The Author(s) 2019

\begin{abstract}
Background The negative impact of institutionalization on children's development and well-being has led to a global recommendation for deinstitutionalization. In countries with weak infrastructure and family support, some children in institutional care have been found to have better outcomes, which may be due in part to the family-like environments created by some Charitable Children's Institutions (CCIs).

Objective The goal was to examine whether and how alternative kinship structures were reproduced in CCIs.

Method Qualitative data from 22 caregivers and 30 orphaned or separated children and adolescents (OSCAs) were collected using participant observation and in-depth interviews, and analysed using a symbolic interactionist theoretical framework.

Results Social interaction with caregivers contributed meaning towards the definition of family within some CCIs, particularly those modeled after a village and/or a single family. These CCIs created a family-like care environment, resulting in OSCAs redefining the traditional concept of family based on consanguinity to one composed of non-kin providing care and support. Social interaction through family-related activities produced novel familial identities, and some OSCAs felt they were part of a quasi-family. However, OSCAs lacked autonomy, feared consequences of not following the rules of behaviour, and felt retraumatized and re-abandoned when they exited the CCIs at age 18.

Conclusion Some CCIs created an "alternative" kinship structure in which most children focused on their education, were provided with basic needs, and formed long-term positive relationships. Despite a number of challenges, family-like CCIs may be a supportive last resort for children without kin to care for them.
\end{abstract}

Keywords Institutional care · Kinship · Orphans · Qualitative research · Symbolic interactionism

Paula Braitstein

paula.braitstein@utoronto.ca

Extended author information available on the last page of the article 


\section{Background}

There were an estimated 140 million orphans globally in 2015, of whom 52 million were in sub-Saharan Africa. This number is based on the broad definition of an orphan as "a child under 18 years of age who has lost one or both parents to any cause of death", adopted by UNICEF and other international organizations (UNICEF 2017). As of 2017, 12.2 million children under age 18 had lost one or both parents due to acquired immunodeficiency syndrome (AIDS) (PEPFAR 2017). While the majority of orphans live with a surviving parent, grandparent, or other family member, it is estimated that there are approximately 2.7 million children between the ages of 0 and 17 years in residential care globally and 286,000 in eastern and southern Africa (Monasch and Boerma 2004; Petrowski et al. 2017; UNICEF 2017). Multiple and complex reasons affect the ability of families to care for their children, including extreme poverty and the complex impacts of human immunodeficiency virus (HIV)/AIDS (Dunn et al. 2007). There is a large number of orphaned and separated children in East Africa, including Kenya, where traditional family and community structures, weakened by HIV and macrosocial change, have been overwhelmed and are unable to cope with the high demand for care and protection of orphaned and vulnerable children (Foster 2000). In Kenya, due to the lack of adequate support structures for family-based care, such as foster care, Charitable Care Institutions (CCIs) have become a source of alternative care (UNICEF Kenya and National Council for Children's Services 2014).

The ethnographic record and guidelines on alternative care (UNICEF and Republic of Kenya 2014) underscore the importance of family-especially consanguinity and descent-in caring for orphaned and vulnerable children. There is, however, some evidence to suggest that the outcomes of children in CCIs in some places may be better, or at least not worse, than their counterparts living in kinship care (Atwoli et al. 2014; Braitstein et al. 2013; Embleton et al. 2014, 2017; Whetten et al. 2009, 2014). It is important to understand how and why this may be the case, given that, until more robust infrastructure and comprehensive services exist to support and protect orphaned and vulnerable children, institutions may remain a "necessary evil". Therefore, research is merited on whether and how alternative kinship structures may be produced and reproduced in CCIs, because the greater extent to which institutions are able to create family-like environments, the more likely children living there will thrive.

Estimates of the number of children in alternative care vary significantly. A study by Petrowski et al. (2017) noted several limitations to estimation attempts including that the existing data on children in alternative care in many countries are weak. This weakness is because many countries lack functional administrative systems for enumerating children in alternative care, and numerous unregistered or unrecorded facilities subsequently hinder measurement efforts (Petrowski et al. 2017). An in-depth discussion of the reasons for institutional care is beyond the scope of this paper. However, there are several drivers of such institutions other than orphanhood, such as family rejection, extreme poverty, abuse in families of origin, disability, mental illness, culture, politics, and societal challenges such as war, conflict, disaster, and displacement/migration. Funding flows and commercial factors are also present in the establishment and sustaining of institutions (Berens and Nelson 2015; Rotabi et al. 2017; Williamson and Greenberg 2010). Research conducted in Uasin Gishu (UG), Kenya, in 2011 indicated that reasons for placement of orphans in institutional care were destitution (36\%), followed by abandonment (22\%), neglect (21\%), physical or sexual abuse (8\%), and lack of an available or able caregiver (8\%) (Morantz et al. 2013). Many orphaned children become street-involved because of poverty, child abuse, 
and family conflict-the leading causes of street involvement globally (Embleton et al. 2016).

Cheney and Rotabi (2014) argue that the proliferation of institutional care for orphans through the promotion of a discourse of orphan rescue has led to the growth of an "orphan industrial complex", which jeopardizes child protection (p. 2). These authors suggest that the broad definition of the term "orphan" by international organizations was promoted in an effort to draw developmental aid's attention to children orphaned by AIDS and that the aid industry's cultivation of the expression "orphans and vulnerable children" emphasized that orphanhood made children vulnerable. This perspective called for, among other things, external interventions of care (Abebe 2009). The "social rupture thesis", which suggests that contemporary orphanhood has overwhelmed African societies' ability to care for their orphans, has also been typified by international organizations like the United Nations International Children's Emergency Fund (UNICEF) (Abebe 2009). Cheney (2017, p. 33) notes that African children in turn have been "constructed as victims in need of rescue", giving rise to "humanitarianism for children produced by NGOs' [non-governmental organizations'] appeal to Western donors to save the needy children of the global south". By building orphanages, "especially in poor communities, children are entrapped in these institutions, alienating them from their families and communities and stigmatizing them" (p. 160).

It is widely recognized that institutionalization has adverse impacts on developmental outcomes and children's well-being (Berens and Nelson 2015; Miller et al. 2015; Smyke et al. 2007; van den Dries et al. 2009; van Ijzendoorn et al. 2008). According to Berens and Nelson (2015), there is strong evidence of devastating developmental consequences for children institutionalized in early childhood. The "effects seem most pronounced when children have least access to individualized caregiving, and when deprivation coincides with early developmental sensitive periods" (p. 388). According to UNICEF, institutions across diverse settings tend

to acquire common characteristics harmful to developing children. Among these are: depersonalisation, or a lack of personal possessions, care relationships, or symbols of individuality; rigidity of routine, such that all life activities occur in repetitive, fixed daily timetables unresponsive to individual needs and preferences; block treatment, with most routine activities performed alongside many children; and social distance, or isolation from extra-institutional society. (cited in Berens and Nelson 2015, p. 389)

Berens and Nelson (2015) suggest that scientific evidence points to the urgent need for deinstitutionalization and the implementation of a policy-driven process aimed at the transformation of child protection services to focus on family- and community-level support ( $\mathrm{p}$. 395).

Much of the evidence on the harmful consequences of child institutionalization (Ghera et al. 2009; Humphreys et al. 2015; Smyke et al. 2007) and calls for deinstitutionalization (Berens and Nelson 2015) derive from studies conducted in former Soviet states. According to Huynh (2014), a number of these influential studies have methodological problems. For example, most of them were limited to institutions characterized by high levels of malnutrition and little or no active experiences, which resulted in a lack of comparison to wellrun institutions that had family-based care options and a lack of research that individualizes children in long-term care institutions and compares them to children in families. Huynh (2014) also mentioned that research conclusions regarding the negative impacts of institutional care did not seem justified by the procedures (p. 390). For example, institutional care has been shown to be associated with poor cognitive development (Berens and Nelson 
2015). However, as Sherr et al. (2017) mentioned, disability has been recognized as a predictor of institutionalization and therefore the "cause and effect mechanisms are hard to disentangle" (p. 32).

Some evidence shows that family- or community-based care is either not an option or, possibly, an option that is worse than living in an institution (Huynh 2014). There is evidence of disparate treatment of orphans within the household. Studies examining orphans and non-orphans in the same household in sub-Saharan African countries found that orphans had lower school attendance rates than non-orphans (Case et al. 2004; Mishra and Bignami-Van Assche 2008). The World Report on Violence Against Children (Pinheiro 2006) indicated that "community leaders in Uganda reported that corporal punishment was more violent and common against orphans than against other children in the household who were more closely related to adult carers or to the head of the household. In Zambia, a study by Human Rights Watch found that orphans who were taken in by extended family members were frequently subjected to sexual violence from uncles, stepfathers and cousins" (p. 69). Recent evidence suggests that, despite the common assumption that extended families provide superior care (Braitstein 2015), CCIs in developing countries may, in fact, produce better outcomes in areas including nutritional status (Braitstein et al. 2013), sexual health (Embleton et al. 2017), basic child rights (Embleton et al. 2014), and mental health (Atwoli et al. 2014). For example, a study conducted in UG County, Kenya, provides evidence indicating that the prevalence of posttraumatic stress disorder was significantly higher among OSCAs in households than those in CCIs, and OSCAs in households had a higher prevalence of sexual abuse than those in CCIs (Atwoli et al. 2014, p. 6). Studies conducted in other low- and middle-income countries (Whetten et al. 2009, 2014) provide evidence contradicting the hypothesis that institutional care of orphan and abandoned children is associated with poorer well-being when compared to family settings or community care. The differences in the study findings were attributed to a number of factors, including the inability of caregivers in these poor communities to provide adequate care in comparison to "positive institutions where children can focus on education and their own needs" and the fact that institutional caregivers in these cultures may provide "parent-like support". It was recommended that the focus of analysis be on the characteristics of orphan care settings associated with improved child outcomes rather than on community- versus institution-based care (Whetten et al. 2009, p. 10).

Institutions are now generally regarded as the last resort, and many countries, including Kenya, have made it policy not to support their construction or renew existing licenses to operate. Newspaper articles (Kabiru 2018; Ndanyi 2018) reported that some children's homes in Kenya were closed due to allegations of abuse and human rights violations, and operating without a license. An online news article (Redazione 2017) indicated that Phyllis Kandie, minister of the East African Community, Labour and Social Protection in Kenya, announced the suspension of registration for CCIs due to allegations that orphanages were "involved in various types of unclear and illegitimate conduct, such as child trafficking". A Department of Children's Services, Ministry of Gender, Children and Social Development, and UNICEF Kenya report (2008) suggested that some CCIs were being operated for income generation by their owners, who "might be open to trafficking children as another way to raise money" (p. 20). The report found that a number of children in registered and non-registered CCIs had not been placed by court orders, were there illegally, had no legal guardian looking after them, and could easily be vulnerable to trafficking, child labour, and other forms of abuse. According to the National Plan of Action for Children in Kenya 2015-2022 report, childcare institutions are being phased out, community-based care is being encouraged, and the recently launched Guidelines for the Alternative Family Care 
of Children in Kenya is slated to be implemented (Republic of Kenya and National Council for Children's Services [NCCS] 2015). The Guidelines for the Alternative Family Care of Children in Kenya proposed a deinstitutionalization strategy (UNICEF and Republic of Kenya 2014, p. 103). The World Health Organization (WHO) and the European Council Expert Working Groups' definition of deinstitutionalization, “a systematic, policy driven change which results in considerably less reliance on residential care and an increase in services aimed at keeping children within their families and communities", inform the Kenyan guidelines (Mulheir et al. 2007, p. 34). The rationale for Kenya's policy focus on providing alternative family-based care and the phasing out of institutional care include violations of children's rights, physical and sexual abuse in institutional care, lack of appropriate aftercare services, and the negative impact of institutional care on a child's social, emotional, cognitive, and intellectual development (UNICEF and Republic of Kenya 2014). The Kenyan guidelines recommend that foster care, adoption, and guardianship should be scaled up; that poverty should never be a justification for placement of children in institutional care; and that institutional care should only be a last resort-but if "deemed appropriate for a limited number of children, it should be provided in a small family-like environment"( $\mathrm{p}$. 5).

A 2016 report, Alternative Child Care and Deinstitutionalization in sub-Saharan Africa, indicates that, for alternative family-based care such as foster care, monitoring visits by social workers in Kenya are infrequent. As a result, "the dangers of neglect or ill-treatment of the child are significant" (Milligan et al. 2016, p. 37). Cooper (2012) argues that, while the Kenyan state is recognized in some policy arenas as a leader in Africa for child protection, a lack of resources impedes the system. The study also notes that the child protection system "further marginalizes children and ignores the conditions of their vulnerability" (p. 495). This finding is supported by a government of Kenya report on the current social welfare workforce, which identified a "shortage of funding which was the most significant bottleneck to advancing a plan" and "a shortage of trained staff, which adversely affects service delivery" (Government of Kenya et al. 2015, p. 14). According to Ucembe (2016), a social worker and former resident of institutional care, the focus on deinstitutionalization is "on the one hand simplistic and demonizes institutional care, while on the other hand, it romanticizes family care" (p. 194). He notes that, while family-based care can become a reality, institutional care still has a place in Kenyan society.

One important component of family-based support is the Kenya Cash Transfer for Orphans and Vulnerable Children (CT-OVC), a social protection program that provides regular cash transfer payments to families living with orphans and vulnerable children (OVC) to encourage fostering and retention of children. The program was scaled up from 500 households in 2004 to 130,000 households and over 260,000 OVC in 2012 (Bosworth et al. 2016; The Kenya CT-OVC Evaluation Team 2012). The program has the potential to improve the lives of many children in Kenya, but it is assisting just a small fraction of those most in need (Bryant 2009). While direct comparisons of children in institutional environments and family-based environments are not common, we and others have found that children in CCIs perform better on some child outcome measures than children in family-based environments, including those in households receiving the government cash transfer (Atwoli et al. 2014; Braitstein et al. 2013). Nevertheless, the cash transfer program does assist children and families in need. Another study on the government cash transfer program to households caring for orphaned children in the county recommends that the program should be expanded due to the widespread poverty and household food insecurity identified (Ayuku et al. 2014). CCIs meet an urgent community need and may be an alternative care environment for children from extended families that are under-resourced 
and overstretched or for children who have no families. In the Kenyan National Standards for Best Practices in Charitable Children's Institutions, the Secretary for Children Affairs indicated that, "[o]ver the last 50 years, CCIs have become critical partners in the support of children who have been abandoned or rendered orphans and vulnerable by a host of factors". The report noted that the Kenyan Department of Children's Services (DCS) "alone cannot manage the care of all these children as has been evident in many rural and urban areas" (UNICEF and Republic of Kenya 2013, p. 6). Based on September 2012 data from the Kenyan DCS, there are over 700 CCIs in Kenya, of which 591 are registered, housing approximately 40,000-42,000 children (UNICEF Kenya and National Council for Children's Services [NCCS] 2014, p. 102). Another report from 2015 states that the number of CCIs is over 830 but that the exact number is unknown, and indicates that CCIs were established to provide care, protection, or rehabilitation of children (Government of Kenya et al. 2015; The National Council for Children's Services 2015).

Our "Models of Care" study identified and described four broad models of care for orphaned and separated children in UG, which included institutional care, family-based care, community-based care, and self-care (Embleton et al. 2014). Further, we found that the organization of CCIs in UG County vary widely, from dormitory-style residences to village-style settings and single-family residences. The dormitory-style living arrangements have large sleeping quarters housing many children segregated by age and sex; they have separate communal living and eating areas, and guardians typically stay within the compound and undertake various domestic, administrative, and caregiving roles. Villagestyle homes emulate typical Kenyan communities and villages and are composed of clusters of houses grouped as family units with a housemother or two house parents, usually living with 12-20 children. As a family unit, children and house parents have their own living space and eat together. Single-family homes have children in care living within a large family unit under one roof; the institution's directors live in the home, acting as the mother and father of all of the children (Embleton et al. 2014). We found that family-based care environments in UG County were less likely to be able to provide for children's basic material needs than were CCIs and may not be able to provide an adequate standard of living. This study, our other work, and our observations in UG County led to the study question for this paper (Atwoli et al. 2014; Braitstein et al. 2013; Embleton et al. 2014, 2017).

It has been recognized that "historically, institutional care has been associated with regimented, depersonalized environments in which children have no opportunity to experience a caring family life" (Powell et al. 2004). As previously noted, institutions have had poor outcomes and were unresponsive to children's needs (Berens and Nelson 2015; Miller et al. 2015; Morantz and Heymann 2010; Smyke et al. 2007; van den Dries et al. 2009; van Ijzendoorn et al. 2008; Wanat et al. 2010). This evidence pointed to the urgent need for deinstitutionalization and the implementation of a policy-driven process aimed at the transformation of child protection services to focus on family-level and community-level support by many governments, including Kenya (UNICEF and Republic of Kenya 2014). However, in sub-Saharan Africa, the orphan situation is complex, and children, especially in countries with weak social support services and where the extended family is under strain (Foster 2000; Milligan et al. 2016; UNICEF and Republic of Kenya 2013), need a safe and effective safety net when living with family is not an option. As we and others have found, children living in institutional environments in sub-Saharan Africa and southeast Asia can have better outcomes on key measures like nutritional status and mental health compared to those living in kinship care (Atwoli et al. 2014; Ayuku et al. 2014; Braitstein et al. 2013; Embleton et al. 2014; Whetten et al. 2009, 2014). Understanding why and how is critical to informing better care environments for all orphaned and vulnerable children, already 
known to have worse outcomes on numerous measures than non-orphaned children (Case et al. 2004; Mishra and Bignami-Van Assche 2008; Pinheiro 2006). We contend that the family-like environments created within many of the institutions in our setting contribute to these better outcomes. With this study, we seek to explore both whether and how alternative kinship systems are produced and reproduced in these institutions to support the resident children.

\section{Traditional Kinship Care and Theoretical Perspective}

In Kenya, the traditional fostering (Umbima 1991) of children through kinship care, defined as the placement of orphaned and vulnerable children informally with extended family or community members (UNICEF and Republic of Kenya 2014, p. 4), became an essential coping mechanism in the face of increased adult mortality due to AIDS and other causes. Families and communities were overwhelmed, and institutional environments quickly increased (Foster 2000). According to Drah (2012), the drastic reduction of economically productive populations as a result of HIV/AIDS and violent conflicts has resulted in a rapid disintegration of the capacity of the customary support system to deal with the increasing number of orphans. In one study, only $25 \%$ of adults in South Africa thought that, in case of their demise, the child's grandparent would assume responsibility for the child. Another $12 \%$ could not name a substitute foster parent. This evidence characterizes the weakened status of kinship structures as a critical agent for the care and protection of children in crisis (Drah 2012; Freeman and Nkomo 2006).

The traditional African kinship structure that children are born into is an intricate and complex system and network of human relationships. Kinship ties through blood (consanguinity) or through marriage (affinity) or even friendships are of fundamental importance because they have a cultural, moral, and spiritual content and therefore must be recognized for their role in regulating and maintaining the life of a community (Kyomugisha and Rutayuga 2011). An African family "normally" includes an individual's direct parents, grandparents and great grandparents, brothers, sisters, uncles and aunts, cousins, nieces and nephews, and spouses and children. However, the concepts of family define far more for Africans than what they mean in the contemporary Western family model. Normally, an African refers to uncles and aunts as fathers and mothers, nephews and nieces as sons and daughters, cousins as brothers and sisters (Kyomugisha and Rutayuga 2011). For example, in Malawian society, an individual is connected to relatives through a broad network of blood relations (Chijere Chirwa 2002).

Kyomugisha and Rutayuga (2011) suggest that, due to the intricate nature of relationships and networks among all the people in the community, the upbringing of an African child becomes a collective responsibility of the community. The immediate family (biological parents and siblings) and extended family provide for the child's physical and emotional needs on a daily basis, and the kinship and community supplement this role by providing for the social needs and any other support in the child's interest. Cultural African normative mandate is that the care of children/orphans is primarily a shared responsibility among all extended family, kin networks, and the local community (Kyomugisha and Rutayuga 2011). In Malawian society, the responsibility for the care of orphans and the processes of social fostering and material provisioning will normally follow the hierarchy of the family structures and kinship patterns (Chijere Chirwa 2002).

As demonstrated by Sudarkasa (cited in Kyomugisha and Rutayuga 2011, p. 189), the raising of children by non-biological parents is a common phenomenon throughout Africa. 
Fostering, a tradition of child circulation, is a common practice in Africa, where children are fostered by extended kin networks and communities, much of which is applicable in the Kenyan context (Cheney 2017; Drah 2012; Madhavan 2004). Drah (2012) notes that "it is the customarily approved arrangement by which biological parents allow their children to be reared by adults other than themselves, either because they are unable to assume responsibility for some of them or for strategic reasons" (p. 4). Fostering sustains bonds of mutual cooperation and interdependence to both parties, and strengthens social and kinship ties through benefits such as access to resources (Cheney 2017, p. 132; Drah 2012, p. 4). However, orphan care in the age of HIV/AIDS is transforming "both fosterage practices and kin obligation, jeopardizing children's well-being and their ability to identify with the blood ties that still form powerful tropes of relatedness for them" (Cheney 2017, p. 131).

One of the major critiques of the research on the institutionalization of orphans is the lack of current theoretical frameworks that adequately reflect the knowledge, values, and experiences of orphans and their caregivers in an institution-based care setting. Therefore, there is a need to examine this specific context in order to identify, describe, and analyze the ideas and social values that inform orphan care in this setting (Drah 2012). Based on the need to apply a sound, contextualized theory-based model to provide in-depth explanations about the production and reproduction of the kinship process within the Kenyan cultural and charitable children's institutional context, we explicitly applied a symbolic interactionist theoretical framework (Hollingsworth 1999; LaRossa and Reitzes 1993; Prasad 2005) in this study. The symbolic interactionism approach to the study of the family has provided a theoretical orientation for family research (Farber 1962). Symbolic interactionism is relevant to family-related research (Stryker 1968, p. 558) and can be used to address questions such as, What determines whether or not a family-related identity is invoked in a given situation? What accounts for the varying degrees of ease or difficulty with which persons adopt novel familial identities? According to LaRossa and Reitzes (1993, p. 136), symbolic interactionism makes a unique contribution to family studies. It emphasizes the "proposition that families are social groups" and asserts that "individuals develop both a concept of self and their identities through social interaction, enabling them to independently assess and assign value to their family activities" (p. 136).

A number of themes and assumptions in symbolic interactionism were used to inform this current study. Specifically, LaRossa and Reitzes (1993) proposed two central themes and associated assumptions in symbolic interactionism that were utilized. The first theme is that "meaning has importance for human behaviour" (p. 143). One assumption associated with this theme is that "[m]eaning arises in the process of interaction between people". Hollingsworth (1999) argues that children in African communities traditionally interact with multiple caregivers, consisting of kin and non-kin. This interaction can give meaning to the definition of family (p. 447). The second theme utilized is the belief that "each individual has a unique self and this self is formed through meaningful interaction within the social group" (LaRossa and Reitzes 1993, p. 144). Its associated assumption is that "individuals are not born with a sense of self but develop self-concepts through social interaction" (p. 144).

There are 44 ethnic groups in Kenya that have "infused the nation with many languages, belief systems, religious rituals, community traditions, and forms of relationships" (Plummer and Njuguna 2009, p. 527). Kenyans strongly identify with their ethnic roots, including parts of the country where their families originally lived, and their ethnic traditions (Plummer and Njuguna 2009). Bratton and Kimenyi (2008) confirm that Kenyans' group identity is tied to their language. Hollingsworth (1999) also argues that an individual's values, attitudes, and self-concepts develop within their own family structure. This finding 
would suggest that, for a Kenyan orphan to develop his or her ethnic identity, one that includes ethnic traditions and language, he or she must do so in a family in which ethnic group members are present. Another assumption is that an individual's identity or "selfconcepts, once developed, provide an important motive for behavior" (LaRossa and Reitzes 1993, p. 144). Behavioural expectations emerge from the process of social interaction. An individual learns how he or she is expected to behave in interaction with others. Behaviour is produced through the role-making process, which is initiated by expectations (Stryker 1968), and the roles we assume provide us with our identities (Prasad 2005). A strong familial identity is more likely to be invoked in a "typical" representative of a strong kinship environment (Stryker 1968, p. 560).

\section{The Present Study}

The present qualitative study was an exploratory investigation of whether and how alternative kinship structures are produced and reproduced in CCIs. Using a symbolic interactionist theoretical framework, the study explored whether a family-related identity can be invoked in children residing in "family-like" institutions in UG County, and, if so, how. Specifically, we examined the social interactions, behavioural expectations, roles and responsibilities, and identities adopted within the institutional environment. We selected this theoretical framework because symbolic interactionism emphasizes the proposition that families are social groups; that through social interaction with multiple caregivers, typical in an African context, individuals develop the concept of self and their identities; and that this interaction can give meaning to the definition of family (Hollingsworth 1999; LaRossa and Reitzes 1993). Exploring how kinship is produced in the Kenyan cultural setting and whether and how alternative kinship structures are produced and reproduced in CCIs is critical to implementing family-based care and developing appropriate supports for children when family-based care is not possible.

\section{Method}

\section{Participants}

The study involved participant observation and in-depth interviews with OSCAs aged 11-23 years old and their caregivers currently living in CCIs in UG County. UG County is one of the 47 counties of Kenya, with its headquarters in Eldoret, about $314 \mathrm{~km}$ northwest of Kenya's capital city, Nairobi. In 2015-2016, UG County had a population of approximately 1133,000 individuals; around $41 \%$ live below the poverty line, with concentrations of extremely poor populations also found in the county (Kenya National Bureau of Statistics and Ministry of Planning and National Development 2018). A county children's officer confirmed that there are 36 institutions (24 licensed and 12 unlicensed) serving orphans and vulnerable children (OVCs) in the county and thousands more OVCs living in the community.

An orphan or separated child or adolescent (OSCA) is defined here as someone for whom one or both parents are dead or absent (UNICEF 2017). This more inclusive definition is justified in this study as it reflects international and national policy and the local reality (UNICEF and Republic of Kenya 2014). However, we recognize that this broad definition of "orphan" may differ from how it is defined in Kenya. For example, Abebe (2009) 
noted that "orphan" and "orphanhood" are conceptualized and understood differently by different societies, and that it is the "phenomenon and mode of life of children that is culture specific" (p. 72). There was no upper age limit on study participants. This eligibility criterion is justified by our aim of collecting information on kinship from those who have exited from CCIs and/or started families of their own. As "former" OSCAs, their experiences remained of interest to the study. Finally, caregivers were defined as the staff (full- or part-time, permanent or temporary) employed in any capacity at CCIs in the study area. Caregivers in the village-style institutions included long-term live-in caregivers, described as house parents by the CCIs (Embleton et al. 2014), who spend the night and significant amounts of time in smaller units with the OSCAs. House parents in this study were married couples and, along with their biological children, lived full time in the CCI. In the singlefamily style institutions, the "parents", as they referred to themselves, were the directors of the home, who lived on site with staff referred to as "aunties" or "uncles", usually working in shifts and performing various chores in the institutions without assigned responsibility for individual children. An "in-charge" matron and aunties and uncles provided care in the dormitory-style institution, the matron usually spending the night there during the week, while staff worked in shifts. Participants, caregivers, and OSCAs were recruited from CCIs selected from among the 20 institutions included in the ongoing Orphaned and Separated Children's Assessments Related (OSCAR) to their Health and Well-Being study (Kamanda et al. 2013). The OSCAR project, funded by the Eunice Kennedy Shriver National Institute of Child Health and Human Development (Grant Number: R01HD060478), is a longitudinal cohort study examining the health outcomes of orphans and other vulnerable children living in different care environments in UG County. Specifically, participants were recruited from CCIs exhibiting three different styles of living arrangements: village-style, dormitory-style, and single-family homes. Specifically, we recruited 30 OSCAs and 22 caregivers from 7 CCIs, all of which are registered. At least two CCIs from each of the three styles of facilities were recruited (Embleton et al. 2014). The sample of CCIs was all mixed-sex institutions. All children currently resident in or exited from a CCI in UG (according to the definitions above) were considered eligible for inclusion in the study. OSCA interviews captured both adolescent residents (11-17 year olds) along with a few adults (18-23 year olds), including those who were no longer living at the facility. Of the 30 OSCAs, 3 were single orphans, 2 had been abandoned by their parents, and 25 were double orphans. All were living with relatives prior to entry into the CCI, except for 2 who were living with friends of the family. Both male and female OSCAs were interviewed for a gender balance. To enhance our understanding of the production of kinship structures at the CCIs, individuals needed to have stories to tell about their lived experiences as either a caregiver or an OSCA at the CCIs.

\section{Procedures}

A purposeful sample of 7 CCIs was selected from among the 14 institutions currently participating in Phase II of the Orphaned and Separated Children's Assessments Related (OSCAR) to their Health and Well-Being study. OSCAR is a 10-year longitudinal cohort study evaluating the effects of different care environments on the physical and mental health outcomes of OSCAs aged 18 years of age or less from 300 randomly selected households, 19 CCIs, and 100 street-involved children. This study conducts annual assessments and facilitates clinical follow-up as needed. For the current study, we recruited CCIs by directly contacting the directors of the CCIs participating in OSCAR. The CCI directors 
granted permission to recruit participants for the study and provided informed consent for the minors. We used a purposeful sampling technique (Patton 2002) in order to meet our participant selection criteria mentioned earlier. This method of sampling allowed us to identify and select the CCIs based on their models of care and to select individuals who were available and willing to participate and share their experiences of living in the CCI and who also had the ability to communicate these experiences and opinions in an articulate, expressive, and reflective manner. All data in this project were collected in situ by the researchers in interviews with participants and observations in CCIs.

The authors declare that they have no conflict of interest. All procedures involving human participants were in accordance with the ethical standards of the institutional and/ or national research committee and with the 1964 Helsinki Declaration and its later amendments or comparable ethical standards. Ethical approval was obtained from the Moi Teaching and Referral Hospital (MTRH) Institutional Research and Ethics Committee (IREC) as well as the University of Toronto Review Ethics Board (REB). All interview sessions were conducted in private rooms. The directors of the CCIs provided written informed consent for children's participation. Individual written consent was obtained from willing participants, both caregivers and OSCAs, aged 18 years and older. Written assent was required for those aged 11-17 years. Prior to the interviews, to enhance participants' understanding of the study, the researchers provided participants with verbal information about the study and assessed their willingness to participate. We were aware that participants' responses might be influenced by the fact that they were current residents of the institutions. To minimize this response bias, participants were interviewed in a private office and outside the presence of a caregiver. They were assured that their responses would be confidential, that their information would be kept anonymous, that they did not have to answer questions that made them uncomfortable, and that they could withdraw from the study after agreeing. After obtaining the signed consent/assent forms, one-on-one interviews were conducted with caregivers and OSCAs. Each interview was conducted in Swahili or English, depending on the participant's preference, and took between $30 \mathrm{~min}$ to $1 \mathrm{~h}$.

At each CCI, participant observation was conducted before embarking on interviews. During this period of participation observation, we gathered information primarily on the social interactions among the members in the CCIs. Due to lack of time and resources, it was not possible to observe participants who had already exited the CCI. For the in-depth interviews, guided by our theoretical perspective and the research literature, we focused questioning on how participants would describe the composition of family. We included questions on who is the head of the family and who is considered part of the family in a "traditional" context, on the nature and function of relationships within the CCI, on perceived affinity and shared bonds with members of the CCI, and on what obligations and responsibilities the participants and others had within the CCI and hierarchies of authority. We also included questions of how OSCAs were integrated into these structures upon arrival at CCIs and how they "graduated" or exited from them later. We avoided asking OSCAs direct questions that could have caused emotional distress, such as questions pertaining to their biological parents. Of note, our research team included a clinical psychologist who could provide emotional support and counseling to distressed participants.

\section{Data Analysis}

Interviews were audiotaped, transcribed verbatim, and those conducted in Swahili were translated into English. An iterative process of data analysis was used throughout the 
data analysis. Both deductive and inductive methods were utilized to identify the coding scheme for the transcripts. The deductive process was guided by the symbolic interactionist (LaRossa and Reitzes 1993) theoretical framework. The inductive process employed thematic analysis (Coffey and Atkinson 1996). "A theme captures something important about the data in relation to the research question and represents some level of patterned response or meaning within the data set" (Braun and Clarke 2006, p. 82). The data were categorized according to repetitions (Ryan and Bernard 2003) and recurrent themes (Green and Thorogood 2009). All authors jointly developed a codebook and completed initial coding together of the transcribed interview data to ensure accuracy. To enhance trustworthiness in this study, we triangulated data from multiple sources such as participant observation and in-depth interviews and literature reviews as a data validation strategy throughout the process of data analysis (Creswell 2007). To increase validity and reliability of the study, inter-rater reliability was also employed, a type of researcher triangulation by which multiple researchers are involved in the analytical process (Kitto et al. 2001).

A qualitative research design was appropriate for this study, as it allowed us to gather rich contextual data of participants' social interaction within the institutional care environment and to be able to use participants' own words to understand the process. The deductive approach to analysis allowed for the development of codes corresponding to symbolic interactionist theory. The research team, using NVivo software, jointly coded interview transcripts by labeling discrete ideas or events related to symbolic interactionist themes and assumptions as described previously: What meaning arises in the process of social interaction between the OSCAs and caregivers in the CCI? Does this interaction give meaning to the definition of family? Specifically, participants were asked to describe the structure of a family. What was the importance of family? What were the roles and responsibility of family members? Did they feel they were part of a family in the CCI? The inductive phase of analysis included the creation of categories and generating concepts as described by Coffey and Atkinson (1996). This process allowed for the organization of the data into meaningful categories: CCI rules and regulations, and limitation of CCI resources. The intention was to examine some of the institutional factors that influence the ease or difficulty with which OSCAs adopted novel familial identities. The data were reduced, allowing the research team to characterize each stretch of the interview data in terms of general thematic content. First, generic categories facilitated the retrieval of different segments of data that dealt with descriptions of the CCI rules and regulations. Second, sub-categories were developed, which included "poor role models". The third and most specific level of category broke down the more general themes into more specific and detailed codes related to the influence of CCI rules and limited resources on the development of orphan identity. Utilizing both deductive and inductive processes of data analysis in association with the symbolic interactionist theory provided further insights into the complex social interactions among OSCAs and caregivers related to the development of a family-related identity through social interaction within the Kenyan cultural and CCI context.

\section{Results}

Analyses of interviews with 22 caregivers and 30 OSCAs identified three main themes: production of kinship in the traditional family structure, reproduction of kinship in the CCIs, and orphan identity. Participants, both caregivers and OSCAs, described the 
traditional Kenyan family structure as "family". Most participants described an extended family structure that was based on "blood" ties (consanguinity).

\section{Production of Kinship}

\section{Traditional Family Structure}

Within the traditional family structure, children developed their family identity through social interaction.

Many caregivers and OSCAs described the traditional family structure as one based on blood relations (consanguinity). All OSCAs lived with relatives or close family friends prior to their entry to the CCI. As mandated by government policy and implemented by the CCIs, there were scheduled annual visits with relatives. Therefore, OSCAs had direct knowledge of the traditional family structure and were able to provide a description.

A family has a number of people and it is just like a tree whereby it is coming up and it is extended. We have ... let's say like from the person who is the head of the family ... like a father ... [mother] ... then the children ... and from the children we have uncles, grandmothers ... it expands as time goes. (Caregiver [CG] 1: Male, age 43) It's just a lineage that you come from, where you were born, brought up ... the family is the people who give you birth. (OSCA 11: Female, age 17)

All participants believed that the father is the head of the household and that, as the primary breadwinner and as sanctioned in the Bible, the father has the authority in the household. Even though Kenyan women are in the work force and are often the head of the household as single mothers, male family members are considered to have primary authority over all family members.

Well, according to me and guided by the Bible, the father is the figure and the leader of the family, the mother is there to help the father, and then the children are there to support their parents. So the leader and the one who will be responsible for leadership of the family is the husband [father]. (CG 12: Male, age 56)

The father [has authority] ... because in the Bible, wives should submit to their husbands because they are superior to them. (OSCA 16: Female, age 18)

Children are part of a complex network of human relationships in the traditional Kenyan kinship structure. Kinship is based primarily on blood ties, with the father as the head of the household in this patriarchal society.

\section{The Importance of Family}

Many described the role of the family unit as being to provide love, basic necessities, security, education, and discipline to children and to teach traditional values. They explained that a family is supposed to be a "united team" that can deal with any challenges that arise. Families work together towards a common goal and towards improving their own welfare.

Basically provision of basic needs for the children and ... then there is ... discipline and then also the norms the traditions that they have to follow, there are some things that they aim at that they want their family to look like. (CG 5: Male, age 63) 
Family is all about relationship, feeling for each other, supporting each. Ah ... rules and regulations to govern it sort like institution. Has norms and a family works together for the common good of all. (CG 8: Male, age 42)

A good family is one where the parents are able to teach their children in the best manner in terms of discipline, good character, and providing them with their needs. (OSCA 17: Male, age 18)

Participants mentioned that the benefits of being part of the family are about having kinship ties, a sense of belonging, and the possibility of inheriting ancestral lands.

You get care, the protection ... you have somebody today ... this is my home ... You have people that you call father and mother ... Apart from maybe education and food ... Maybe land, you know like our Kalenjin land is very important. If your family has land you benefit from that. (CG 15: Female, age 38)

Gives a sense of belonging which motivates you in life and having a place to call home. (CG 9: Male, age 38)

Each family member had a role and responsibilities towards each other. Parents' roles are providers, disciplinarians, and teachers of Christian values and traditional norms. Children's responsibilities are to respect and obey their parents, work hard in school, and do their chores. Children are grateful for the care they receive in the traditional family structure, and the perception is that their lives would be stress free because all their needs would be met within this home environment.

Also the norms ... the traditions that they have to follow, there are some things that they aim at that they want their family to look like. (CG 5: Male, age 63)

The core thing is love ... so when I show them love it is the father's love and when the mother loves them it is the motherly love. (CG 10: Male, age 41)

I think that they have [responsibilities]. For example when a child goes wrong, the parent has to discipline the child and also the child when she/he sees that their parent is drunk, they try and correct them and teach them about Christ. (OSCA 16: Female, age 18)

The mother is the nurturer ... the father is the provider makes sure that the children get food and pays school fees for the children. The child is thankful and the child gets comfortable and does not have any stress because they get everything the father provides ... respect the parents and do what they are told. (OSCA 6: Female, age 19).

The importance of the traditional Kenyan family structure is due to its moral, ethical, spiritual, and cultural content and its ability to meet the physical and emotional needs of children on a daily basis.

\section{Changing Landscape}

Based on our research findings, it appears that poverty was one of the key reasons for the placement in a CCI of a number of the OSCAs interviewed. There were strains in social relations, and the traditional extended family structure of Kenyan society was not able to deal with the crisis of children in need of care and support. Many of the OSCAs lived with relatives before being brought to the CCI. Often, relatives were unable to care for orphan children due to poverty.

My aunt is the one that brought me to the children's home $[\mathrm{CCI}] \ldots$ I had stopped 
going to school because there was no one to pay my school fees. (OSCA 26: Male, age 24)

Our grandmother took us and we stayed with her ... we started to have jiggers ...

My grandmother was not stable enough to take care of us ... because of lack of food and facilities to accommodate us. (OSCA 28: Female, age 17)

Ageing grandparents were often not able to physically or financially provide for the children in their care. Aunts or uncles could only meet the needs of their own biological children. When faced with the challenges of caring for orphans, traditional family networks opted to place these children in institutional care.

\section{(Re) production of Kinship in the Charitable Children's Institution}

\section{Family-Like Care Environment}

The study found that house parents in the village-style CCIs were married couples living full time with their biological children along with the OSCAs in their care. In the single-family CCIs, the directors were the parents/grandparents living at the CCI. These individuals were the primary caregivers and had frequent social interactions with the OSCAs. The in-charge matron was the administrative head of the dormitory-style CCI and did not live full time at the CCI, was not the primary caregiver, and had less social interaction with OSCAs. OSCAs addressed their caregivers as grandparents, parents, aunties, or uncles. These terms are culturally determined in the traditional Kenyan family context based on the hierarchy of authority, and replication of this form of address in the CCI would be natural and respectful. This form of addressing their caregivers may have assisted with developing a family-related identity in the CCI.

In the CCI, children's idea of family is reconstructed and redefined; several children said that family were the people who took care of them, provided for their needs, and educated them. Many of the activities organized by caregivers in the CCIs, such as daily devotions, eating together, and doing homework together were to create a family-like environment and encourage emotional bonding. Also, through discourse, caregivers may have shaped how the CCI family was redefined.

The CCIs, particularly the village-style and single-family models included in this study, were self-described as family-like care environments. The following is a caregiver's perspective of village-style care environment.

In this place we have four families ... we are a family... We are run by one director ... we have devotions, we have rooms for boys and girls the same, the same meals. Because we are here full-time, we are dedicated to do that [caring for the children]. We can say we have been called to serve ... we are happy to provide the basic needs for these children. As parents we have to love these children so that they may belong. That is why we are brought together, because of the love and spiritual nurturing. (CG 6: Male, age 45)

We have one new child who came last year and the responsibility we took as parents was to welcome him and let him know that I am the father and she is the mother and so that he is able to feel that motherly love and the fatherly love. (CG 10: Male, age 41) 
Here, we train them to feel as though they have parents and that they have a family so we get so close to them ... For these children here, you have to give them so much affection so that they can feel like they belong. (CG 17: Female, age 48)

The CCIs cultivate a family-like care environment that includes daily devotions and regular communication with the children. Under the direction of "babu" (grandfather), the director, house parents in the village-style CCIs spoke of creating unity and bonds within the "family" through social interaction and socialization of the children. House parents mentioned that it was their role to provide moral support, love, and acceptance and to foster mutual understanding and respect. They provided a place where the children can feel at home, feel a sense of belonging, and feel like they have parents and siblings.

Actually the relationship is good because we have programs that we all attend to make sure that they [OSCAs] are well in the morning and everything is set. We also eat together during lunchtime and then we have a devotion where we normally pray as a family and that brings the bonding. (CG 9: Male, age 38)

Caregivers and children believed that kinship based on lineage was important because human beings were created in such a way that the sense of belonging and having roots was important to them. However, as one caregiver noted, "Today someone can be grafted into a family even though they are not born into it. They could be adopted, or brought in or fostered into a family and treated as a member of that family".

My family is anybody who's ready to hear me and ready to play a role that is important in my life. The family here is my brothers and sisters who were ... we are here together from different backgrounds and the parents who were brought here to care for us because for them, we're their children, despite them having other children, their biological children. (OSCA 21: Female, age 19)

Family activities within the CCI, the care, guidance, and education provided, gave children a sense of belonging and a sense of family.

My family is those that took care of me that at that time, when my parents died, that children's home $[\mathrm{CCI}]$ that took care of me are my family. It was a very good relationship in there. I felt at home, they took care of us, and since all that time I have been receiving everything I want when growing up. I felt as part of the family. I don't really see any difference because the role of parents anywhere is giving the children their basic needs, giving direction and guiding but when our parents died we suffered for a short while but when we were given exactly what our parents would do so there is no difference. The fellowships we had together, the devotions, getting involved in family activities that made me feel that actually that was home. (OSCA 26: Male, age 24)

The children's home $[\mathrm{CCI}]$ is a very valuable family to me. I have stayed with them longer than I have stayed with my own family. I was raised there; I got to know God and learnt a lot. The home is a huge family to me. (OSCA 27: Male, age 24)

Many participants, both caregivers and children, indicated that after they had "exited" the CCI, they would keep in touch and return frequently because of the family bonds they built there. Caregivers felt that they would be grandparents to the children of the orphaned children they raised. Children interviewed also indicated that their CCI parents would be grandparents to their children because those parents were the only parents they knew. 
Children also wanted to give back to the CCI and help other children growing up in the institutions.

[I will still be connected] ... it is because they have taken care of me ever since I was young and they have mentored me ... and therefore I feel like part and parcel of them. (OSCA 14: Male, age 18)

We have a program every time schools are closed we go twice in a holiday we go and talk to them [OSCA siblings] and encourage them and stay with them, every time I go there because there I have guardians who took care of us ... we are the pioneers and we must go for them to check on our progress. As a child there is a home where you will always go back to check on your family members and feel at home. (OSCA 26: Male, age 24)

Caregivers and children's roles and responsibilities in the CCI were similar to those in the traditional family structure. Caregivers at the CCI assume the typical parental roles such as providers, disciplinarians, and teachers. As parents, their role also includes completing the initiation rites for young boys in their care.

A lot of counseling is done in this place, we counsel, discuss, share, encourage... For example, during the circumcision, we shared with the children, and they were ready and looking forward to it ... the boys knew exactly what to expect ... we also had a thanksgiving ceremony. Indicating that now the time has come, that stage is gone, you come back to the society and that you should act as a mature person now and don't just behave like anybody anywhere, be responsible. (CG 12: Male, age 56)

In addition to respecting their parents, going to school, doing chores, children are role models and have responsibilities to each other. Similar to the traditional family structure, older siblings were role models and often provided care and guidance to their younger siblings.

Yes, I'm responsible for my siblings. I show them the direction, for example in the academic work. I have to be hardworking so that they can see what I'm doing. (OSCA 11: Female, age 17)

Studying hard, being respectful and again show that indeed you can be a reference [role model]. (OSCA 30: Female, age 21)

A family-like environment in these institutional care settings provided the orphans in their care with a sense of family and the opportunity to build lifelong family bonds and to be role models to their siblings.

However, children often experienced challenges in belonging to this quasi-family-like arrangement, particularly in the dormitory-style institutions, where primarily "aunties" and "uncles" instead of "house parents" provided care. Aunties and uncles usually did not live with the children on a daily basis and were there to look after the children's physical needs; social interaction was limited, which did not allow for emotional bonding. There appeared to be conflicts between the children and caregiver in this style of institutional care.

I got one recommendation that those who are employed to work in the children home [CCI] should be good hearted and those who have studied how to handle children because there was a time when some were employed and they harassed the kids. (OSCA 26: Male, age 24)

I can do something that may make them angry at me ... I would say it is these aunts is responsible ... at that moment we can collide. The main challenge is few workers 
working here and there are very many young kids who really need adult help. (OSCA

5: Female, age 21)

The staff may have different relationship with other children ... some are closer. The staff here should treat all the children here fairly. (OSCA 17: Male, age 18)

While the single-family-style arrangement also had "aunties" and "uncles", there were "parents" as head of the institutions. The parents were part of the children's lives and had more opportunities to interact and bond. These parents were often the directors caring for all the children in the institution. The village-style setup appeared to have had the most favorable opportunity for social interaction and family bonding, as there were several married couples in the role of "house parents" to smaller groups of children. Through interaction with their caregivers, children appeared to have assigned meaning to the family-related activities and may therefore have felt that they belonged to a family.

\section{Adapting to Institutional Care}

Adapting to institutional care depended on how young the child was when first brought to the CCI. It also depended on the child's circumstances prior to coming to the CCI and how he or she was treated in the institution. Several children mentioned that they were very young when they were placed in the CCI and could not remember how long it took them to adapt to institutional care. One female participant mentioned that her parents abandoned her and her disabled sister; they lived on the streets before being taken to the government's rescue centre, where they stayed for 1 year before being placed in the CCI. For her, adapting to the CCI's environment was fairly quick, probably due to the fact that in her previous environments she was neglected and abused. Ethnic differences, specifically, predominantly using their vernacular language, presented a challenge to the adjustment period.

I found it hard to adapt because there were many children around. Some could even speak to me in their own mother tongue. As time went, I adapted. We spoke to each other as children to create the good relationship between us. (OSCA 14: Male, age 18)

For me, personally, I was used to my grandmother and I was used to speaking that vernacular language. So coming to [the $\mathrm{CCI}$ ], being taught English, being taught Kiswahili, no one can understand you when speak your vernacular language, it was hard. (OSCA 29: Female, age 21)

Immediately I arrived, it did not take me long [to adjust]. Parents inside here are not bad unlike those ones out there. My parents were not good ... They could not take me to school and they left me to take care of myself ... looked for food [lived on the streets]. I do not know [where my parents are]. (OSCA 8: Female, age 15)

I adapted quickly because I was still very young so when I came, this place was better than where I came from, I picked up very fast because I got everything. (OSCA 11: Female, age 17)

Adapting to their new environment meant that OSCAs lost ethnic connections, cultural traditions, and language. OSCAs in these CCIs are unable to develop their ethnic identity, one that includes ethnic traditions and language. 


\section{Differences from a Traditional Family}

A significant difference from a traditional family structure is that children in institutional care have to exit at a specified age, usually 18 years of age, as mandated by the government. Other differences were that the children in the CCI tended to lack personal possessions, could not have cell phones, had shaved heads, followed rigid scheduled activities such as daily devotions, and were mostly not allowed to socialize outside of the institution.

The difference is that here is like a routine ... and you know in your home when you feel hungry you just go and say mum I want this and you know ... Then again their demands are not like when it is in your family, so they cannot say that I am tired of eating this and this I wish I could eat this and this ... they do not, they will never ask about that for example. So that freedom of expression is not there in a setup like this unlike in a family. (CG 15: Female, age 38)

In the family out there maybe you are free but here you don't have that privilege ... Also ... [no] privacy (CG 16: Female, age 34)

In here, we are restricted to staying only here but the other families can move out to wherever they like, they have freedom. We only do what is required for us to do. (OSCA 14: Male, age 18)

These constraints and strict regimens often do not exist within the family structure. In the CCI, these restrictions appear to diminish children's capacity to be active agents and to have any decision-making ability, freedom of choice, or expression.

Government policy require CCIs to exit children from the institution at age 18 (UNICEF and Republic of Kenya 2013, 2014). As this study found, the CCIs implemented this exit strategy in a way that included annual visits to any relatives they were able to locate in an effort to familiarize the children with their relatives. Some CCIs in this study had exit strategies in place that included a youth pastor who followed up with those leaving the institutional care environment.

Normally after high school they leave the home because we believe that they are above $18 \ldots$ so they go live with their relatives or their guardians in the villages... if they go to college we support them but when they complete college we withdraw our support ... unless there is a need we don't see them coming when they feel like ... we have a youth pastor who does follow-ups so every month he has to give a report of how many he has visited and find out what they are doing and what they are feeling and so we get the statement... so they are very grateful for all the support they are given ... are surprised that we still follow them even after leaving here. So they are so grateful and they appreciate that because they feel that there is somebody who is concerned. (CG 5: Male, age 63)

Another difference from the traditional family structure is that children who fail to adhere to the strict rules of the institution, as determined by the donors and directors, are expelled from the CCI.

We had three boys who were sent home because of their behaviour and character while in school. The rules here are if you misbehave and maybe chased out of school, you do not stay here. You will have to go back to your people ... because you will not be a good example to these children ... the things that we would want to change are, if the child is not performing in school and have to leave the home at 18 years, they 
need to stay longer to be helped because they would go back to the same problem at home. (CG 6: Male, age 45)

Children were not able to practice their vernacular languages, belief systems, religious rituals, and community traditions in the CCIs. Traditional practices and beliefs that are of importance in the ethnic groups are not incorporated in reproduction of kinship care in the CCIs. This policy meant that OSCAs lost the part of their identity that is tied to their ethnic roots and traditions. That loss has implications for OSCAs leaving institutional care.

I have had a hard time reuniting those who have guardians or relatives, very difficult time, trying to counsel and encourage them to reunite with their uncle or aunt. It has been very difficult because the children already feel they belong [in the CCI]. (CG 12: Male, age 56)

So it's like here I was raised since I was young. They have educated me, I have gone the wrong paths, they have corrected me till the place am now. So I can call them my family $[\mathrm{CCI}]$, because in my real family [relatives], they don't know the real me, so these are the ones who know the real me. Even if they are taken somewhere, they can explain who I am more than my real family [relatives]. (OSCA 28: Female, age 17).

A caregiver mentioned inheritance of ancestral land as an important benefit to being part of a family, specifically mentioning the Kalenjin ethnic group. An OSCA believed that belonging to the traditional family is based on "lineage that you come from, where you were born". OSCAs who experienced long-term institutional care have lost connection to the place they were born and would most likely not benefit from inheritance of family land, and many would not be able to trace their lineage. The CCIs do not offer a deep connection to the children's "roots", lineage, or benefits from inheriting land. Those who have exited the institution have noted that they had a difficult time with this transition. Essentially, family support is withdrawn; those leaving care no longer have emotional support from and regular contact with their caregivers or siblings. Due to long-term residence in the CCI, they do not have strong ties to their relatives and community. Their sense of belonging would most likely be affected, and their orphan identity would be reinforced.

\section{Orphan Identity}

A number of key themes "emerged" that conflict with the family structure reproduced in the CCI. These include what happened to the children when or if they failed to meet CCI expectations, when they turned 18 years of age, or if they did not adhere to the strict rules of the Christian-based institution set out by the international donors. Another theme was the stigma associated with being an orphan in institutional care. These institutional factors appear to contribute to some children retaining their orphan identity.

\section{Not Meeting Expectations and Being Poor Role Models}

Kenyan citizens and residents do most of the actual caregiving and are primarily responsible for creating the family-like environment in the CCIs. However, the CCIs in this study had guidelines set out by their usually foreign donors on eligibility for entry into, and criteria for expulsion from, the institutions, also influencing how kinship care is reproduced. The donors and directors of the CCIs are thereby also defining the relationship and the stability and permanence of these relationships. The CCIs have strict rules on appropriate behaviour in keeping with Christian values. Children must maintain acceptable grades in 
school or risk being "chased away" from the CCI. As one child mentioned, she does not know if she would be welcomed back to the CCI for visits if she is asked to leave due to poor grades. Being poor role models due to misbehavior in school or teenage pregnancy are other reasons for immediate expulsion from the CCIs. As one girl mentioned, her sister was asked to leave the home due to her pregnancy. She felt that there was no room for making mistakes and being forgiven, that you can only feel you are part of a family when they stand by your side in times of difficulty or when you make a mistake.

At the moment they used to say that regardless of the grade you will get they will support you but right now they are saying that they will support you if only you will get $\mathrm{C}+$ so I pray that I get a good grade so that I can be part of the family. I won't be sure if I will be welcomed here. (OSCA 5: Female, age 21)

Sometimes you feel it's there [a family] but I have my sister who had not finished school but was chased away when she got a baby, if she were in an African home she would be told to continue with school and the mother would take care of the child. (OSCA 25: Female, age 18)

Being asked to leave the CCI for misconduct or not meeting expectations appears to suggest that being part of the CCI family is conditional.

\section{Exit Strategy}

Government policy documents state that children are required to leave the CCI at 18 years of age, and the CCI has to implement an exit strategy (UNICEF and Republic of Kenya 2013, 2014). If these children are in school, they receive financial support, but if not, they are repatriated with relatives if possible or they are supported on/off site by the CCI for a period of time.

Sometimes we have that bond to follow our child to high school or wherever he is going, and from that high school somebody else takes it from there and it is creating and we have a vacuum within us. (CG 1: Male, age 48)

I don't see any challenges I faced growing up ... I got everything I wanted ... the main challenge maybe was leaving the children's home. (OSCA 26: Male, age 24)

It is a difficult transition for both caregivers and children. For children, it is the only family and home they know, and returning to live with relatives they barely know or to live on their own is challenging. The house parents often reported feeling a void in their lives due to this loss of regular contact with the children they have bonded with. For those leaving care, this disconnection from a familiar environment and social support may lead to the loss of a sense of belonging, a sense of being abandoned, psychological distress, and the (re)assertion of their orphan identity. Leaving care at a predetermined age is not consistent with the traditional kinship structure, and the sense of loss may be compounded by the lack of connection to blood relatives and community members, and the loss of their ethnic identity.

\section{Stigma}

Another issue that had an impact on the children living in CCIs was the stigma they experienced when it became known that they were orphans. For example, their orphan identity 
was highlighted during school visitation days when caregivers were not able to visit or brought little in the way of gifts and food during the visits.

At times in school visitation some of us are not even visited and when visited they bring for us a limited amount of things unlike the other children who are brought for everything. We share stories in the dormitory and they say what they were bought and we may feel embarrassed to even say. (OSCA 14: Male, age 18)

The label "orphan" can be a stigmatizing one, and children's perception of stigma due to their orphan status could lead to the (re)emergence of their orphan identity.

The rules and regulations of the CCI have implications for how kinship is reproduced and, consequently, the OSCAs' sense of belonging. The perceived stigma associated with institutional care and the government-mandated policy on the age a child must exit the CCI might have an impact on children's long-term well-being.

\section{Discussion}

Our findings from 52 interviews with caregivers and OSCAs reveal the complex social interactions related to the development of a family-related identity through social interaction within the Kenyan cultural context and the CCIs. As indicated, our goal was to understand how kinship is produced in the Kenyan cultural setting and whether and how alternative kinship structures are produced and reproduced in CCIs. Overall, many of the children who participated in this study felt that the care and guidance they received in the CCI was similar to the care they would have received in a traditional family setting. Most believed that they were part of a quasi-family in the CCI, that they had parents, aunties, and uncles who cared and provided for them, and that they had siblings with similar life experiences. Many also felt that they had lifelong connections to their caregivers and siblings within the CCI. The CCI parents and other caregivers who fostered the children in their care transformed the traditional family structure; the family structure was redefined. According to the OSCAs, family was not just those individuals who were blood relations but was now defined as anyone who provided care and resources. While many OSCAs adopted a quasifamilial identity within the CCI, it differed, depending on the child and the circumstances from which he or she came and his or her treatment in the CCI. The younger the child, the faster he or she was able to adapt to the CCI setting and adopt the familial identity with more ease. An older child took longer and had more difficulty because of the barriers of vernacular language and the trauma of the loss of family. However, older children adapted quickly and adopted the familial identity with more ease if they came from more challenging backgrounds, because the CCI provided them with a safer environment. Some children did not fully adopt the familial identity. Instead, their orphan identity was more prominent because of the CCI rules and regulations. Due to challenges and constraints in the CCIs, there was mention of conflict in relationships with caregivers, the lack of autonomy, lack of freedom, and the stress of not meeting expectations and transitioning out of institutional care. Lineage, where an individual was born and raised, and the inheritance of ancestral lands were considered important factors of the traditional family structure. Many OSCAs in long-term institutional care lost their connections to their family homes and to extended family.

Through social interaction, children appeared to have assigned meaning to the familyrelated activities and adopted novel familial identities. The CCIs encouraged family-related 
activities such as praying together, doing homework together, helping and being roles models to younger siblings. The "parents", "aunties", and "uncles" of these institutions provided care and support, looked after the OSCAs' basic needs, and ensured they received an education. In turn, OSCAs respected their parents, completed their assigned chores, and attended school. These social interactions gave meaning to the definition of family and, as reported by many of the children interviewed, created a new definition of family within the CCI. The evidence suggests that caregivers and OSCAs within the CCI social structure had specific roles and responsibilities, and, as a result, they behaved in a socially expected manner in their positions as a parent or a child in this home. The role they took on provided them with their identities. Many of the children reported that they felt they were part of a family. This finding is consistent with other findings that indicate a "family-like environment was created primarily through the staff's articulation of, and identification with, family roles" such as father, mother, brother, and sister (Neimetz 2011, p. 585) and that these family-linked identities - mother, father, or aunt— "made possible the successful creation of a family-like setting" (p. 594). Neimetz (2011) also noted that, through these roles and the consistent routines established at the institution, caregivers expressed that the children mattered to them. This author also argued that the consistent routine was the "foundation upon which [children] can thrive physically, mentally, emotionally and spiritually" and "define who they are" and "who the family is". Adopting this familial identity was due to the kinship environment created by some of the CCIs, particularly the village-style and single-family models of care.

According to Prasad (2005), different social situations could lead to the prominence of some identities over others. This could be the case when children's orphan identity became more prominent if they failed to meet the CCIs' strict code of conduct. OSCAs were concerned about not getting good grades to ensure their continued support by the CCI and feared the consequences of not adhering to Christian values; for example, getting pregnant or misbehaviour meant they were no longer considered a good role model and could no longer be part of the CCI family. Any conduct that did not meet the Christian values of the CCI often meant that OSCAs were expelled. Also, children had to perform at a certain level in school or they, too, would be expelled from the CCI. Those children felt that the CCI was not a true family, because, in a traditional African home, if they made a mistake, they would not be thrown out of the home. This finding suggests that institutional care may not provide adequately stable, consistent, and permanent care found in most traditional kinship care structures. While Kenyan citizens and residents do most of the actual caregiving and are primarily responsible for creating the family-like environment, the CCIs' foreign donors determine the guidelines on eligibility and criteria for expulsion in the institutions. Therefore, the donors and directors of the CCI are also defining the relationship and the stability and permanence of these relationships. Belonging to the CCI family was conditional and based on the criteria determined by the CCIs and their donors.

While there was no mention of physical or sexual abuse in the CCIs in this study, there were verbal conflicts, particularly in the dormitory-style institutions. Evidence from another study indicated "living in institutional care appears to independently protect orphaned adolescents in this setting, especially from sexual exploitation (i.e., exchanging sex, sexual violence), compared to orphaned adolescents living in family-based care" (Embleton et al. 2017, p. 422). In the single-family and village-style family-based CCIs, house parents were mature people with formal training in childcare. Caregivers in dormitory-style institutions were usually not as experienced or well trained in comparison, and the caregiver to child ratio was higher compared to the village-style CCIs. Conflicts could be the result of the quality of caregiving in the different models of care. Powell et al. 
(2004) suggest that psychological disturbance was higher in dormitory-style than in familystyle institutions, which was attributed to the quality of care and caregiver to child ratio in institutional care. Our data indicate that CCI rules and well-structured regimens deprived OSCAs of autonomy and freedom, which may have implications for their sense of self and self-concepts about their identity and attributes. Powell et al. (2004) indicated that the regimented environment meant children did not fully develop the capacity for independent thought and motivation, which would make it difficult for them to cope outside of the institutional environment.

Government policy as outlined in the National Standards for Best Practices in Charitable Children's Institutions and the Guidelines for the Alternative Family Care of Children in Kenya state that "a child shall exit a CCI when he/she has attained the age of 18 years" (UNICEF and Republic of Kenya 2013, 2014). These two policy documents (UNICEF and Republic of Kenya 2013, p. 75; 2014) also state that a detailed plan for exit strategies must be in place for children leaving the care of the CCI. As one document noted, "The implementation of an exit strategy is the process in which a child leaves or transits from a $\mathrm{CCI}$ in an explained, planned and sensitive manner. The Management of a CCI is responsible for the preparation, transitional arrangements, and after care follow up of each child" (UNICEF and Republic of Kenya 2013, p. 75). The exit strategy mandated by the government and implemented by the CCI meant that OSCAs were no longer in regular contact with their CCI parents and siblings, and their connection to the CCI was through the youth pastor or at annual reunions. Some were repatriated with distant relatives in homes that were very different from what they were accustomed to. The transition was very difficult for many OSCAs. This finding is supported by other former residents of institutional care, who indicated that they lacked the necessary life skills and support to cope with life after leaving the CCIs and that they felt stranded and lonely, re-abandoned and re-traumatized (Roeber and Kenya Network of Careleavers (KNCL) 2011; Ucembe 2016). Experience of long-term institutional care often alienated children from their extended families, communities, and culture, which would have "serious implications for the eventual re-integration of orphans into their communities and for their future happiness" (Powell et al. 2004). OSCAs experienced stigma due to their orphan status living in institutional care (Cheney 2017, p. 160). For example, a study in Zimbabwe found that the village-style homes did not blend and integrate with the surrounding communities because the "villages contained environment, architecture and superior quality of the housing that set them apart from the community and caused the children resident there to be readily recognized as orphans. The inmates are often perceived as privileged by the surrounding community and this has the effect of engendering resentment and increasing stigma" (Powell et al. 2004). It was found that, for residents who age out of care in Ethiopia, the stigma associated with institutional care placed them in "positions of vulnerability and risk in many significant domains of their lives" (Pryce et al. 2016, p. 128). These circumstances gave prominence to their orphan identity for some OSCAs.

Studies have shown that many orphans have lost their inherited properties to land-grabbing extended family members (Drimie 2003; Roby 2011). It has also been found through anecdotal evidence that extended families in western Kenya "are reluctant to accept orphans because they do not want to have to include the orphaned child in inheritance plans" (Braitstein et al. 2017, p. 341). Attachment to family property may help orphans with their psychological well-being by providing them a measure of economic security, improving their future outlook, decreasing their worries about discrimination and isolation, and being "an outlet for continued emotional connection to the deceased parent(s)" (McPherson 2006, p. 23). As the data indicate, the loss of the connection to extended 
family and land meant the loss of children's ethnic affiliation, loss of their vernacular language, and disruption of their traditional kinship ties. This loss of ethnic identity within the CCI may be of major significance in the Kenyan context. Research on colonial and postcolonial Indigenous residential schools suggests that many school children experienced a loss of culture, language, and traditional values (Elias et al. 2012, p. 1561; King et al. 2009). It was found that, in Indigenous societies, "traditional teachings and knowledge provided a basis for positive self-image and healthy identity", and community elders were a vital part of this process (King et al. 2009, p. 78). It was also suggested that "language was crucial to identity, health, and relations and identity was a necessary prerequisite for mental health" (p. 78). In Kenya, where people strongly identify with their ethnic roots (Plummer and Njuguna 2009) and their identity is tied to their language (Bratton and Kimenyi 2008), the loss of ethnic identity has implications for the OSCAs long-term self-image, health, mental health, and social relations.

An important strength of this study was its documentation of the viewpoints of a wide variety of actors, orphans, and caregivers in the different models of institutional care. In focusing on the orphans' perspective, this paper was able to provide a unique insight into their sense of belonging and their ability to adopt a quasi-familial identity within the various institutional care environments. The study was also able to describe the characteristics of orphan care settings that are associated with improved child outcomes rather than comparing community versus institution-based care. Specifically, we were able to differentiate our results by type of CCI, finding that those institutions modeled as single-family dwellings or as village-style homes seemed to have a substantial impact on participants' perceptions about whether and how kinship was produced. Situating the study within the existing OSCAR study allowed the identification of a representative sample of all children aged 11-18 years living in institutional care and institutional care-leavers aged 18-23 years.

There are also limitations to this study. The study was designed to provide an in-depth understanding around whether and how kinship is reproduced in the CCIs. This approach focused on a limited number of children. While this study is likely to have been effective in providing a comprehensive understanding of the family roles and social interactions involved in creating a family-like environment, it is important to note that the small sample size and the fact that the CCIs included in the study were Christian-based institutions primarily funded by foreign donors may limit the generalizability of the findings. We were aware that orphanhood and institutionalization were sensitive issues and tried to further minimize distress to participants by not asking direct questions that could be upsetting, such as questions related to the loss of biological parents. However, such questions may have further enriched the data and provided a broader understanding of the challenges to the reproduction of kinship care in CCIs.

The findings of this study are consistent with the supporting literature that African children interact with multiple caregivers including non-kin. From a symbolic interactionist theoretical perspective, this process of interaction gives meaning to the definition of family (Cheney 2017; Chijere Chirwa 2002; Drah 2012; Hollingsworth 1999; Kyomugisha and Rutayuga 2011; Madhavan 2004). The symbolic interactionist perspective also assumes that individuals develop a sense of self through this interaction (Hollingsworth 1999; LaRossa and Reitzes 1993). As the study findings indicated, some OSCAs adopted a quasifamily identity as a result of the social interaction that occurred in the CCI. However, there were challenges to the reproduction of kinship care in the institutional environment that made it difficult for some OSCAs to assume this family identity. While some CCIs provided parent-like support in a family-related environment, strict rules and regulations resulted in OSCAs being afraid of expulsion for not obeying the rules; some also experienced a sense 
of loss when family support was essentially withdrawn after they exited at a predetermined age. Some CCIs lacked well-trained permanent staff, which led to conflicts with OSCAs. Also, CCIs did not foster a sense of independence by allowing OSCAs to have autonomy and freedom, which had negative consequences for OSCAs when they exited institutional care. OSCAs did not have access in the CCIs to important symbols such as their vernacular language and traditional rituals, which facilitate their ethnic identity. Consequently, the challenges to the reproduction of kinship care in CCIs resulted in some OSCAs retaining their orphan identity, which was further compounded by their alienation from their communities and extended family members due to long-term institutionalization.

Parent-like support and family-related environments might be associated with the positive outcomes of OSCAs within the CCIs (Atwoli et al. 2014; Braitstein et al. 2013; Embleton et al. 2014, 2017), which are consistent with findings of other studies (Whetten et al. 2009, 2014) conducted in similar low- and middle-income countries. Some CCIs provided a positive environment where children were able to focus on their education, were provided with their basic needs, and formed long-term positive relationships. Many of the children came from extended families and environments where they did not receive adequate care due to the strain on the traditional family resources and other domestic issues. Neimetz (2011) indicated that the children's health might lie in how caregivers were able to maintain the dynamics of a traditional family in an institutionalized setting. It is also possible that better health outcomes, particularly mental health, is due to the fact that traditional fostering is a common practice in sub-Saharan Africa, where children are raised by multiple caregivers consisting of kin and non-kin and therefore have the opportunity to live with better-endowed adults (Drah 2012; Hollingsworth 1999). As this type of caregiving is a common cultural practice in Kenya, it is possible that children find their improved future outlook provided by the CCI a more acceptable alternative than living with impoverished or abusive extended family members.

Differences between institutional care and traditional kinship care indicated that reproduction of "traditional" kinship care was not possible within the context of the CCIs. However, the CCIs did produce an "alternative" kinship structure and a family-like environment in which OSCAs could thrive. Neimetz (2011) found that, while not a family in the traditional sense, some institutions established a family-like environment through identification with explicit roles and inclusion of particular daily routines "where children receive[d] the emotional nurturing needed for healthy development” (p. 594). Inadequate family-based care structures as well as inadequate provision of financial support for families taking care of orphans suggest that there is still a place for institutional care in Kenya (Ayuku et al. 2014; UNICEF and Republic of Kenya 2013). The family-like institutional care environment, particularly the single-family and village-style models, may be a safe and effective alternative safety net for children in this setting. Clearly, there are challenges that need to be addressed with alternative care, including abuse within institutions, children in institutional care being "alienated from their families and communities", stigma associated with institutional care, and inadequate preparation for the transition of youth to the outside world (Cheney 2017; Powell et al. 2004; Pryce et al. 2016).

In the study area, extended family members traditionally care for orphans. Urgent efforts and investment are required to complement these community and family resources with adequate social protection and welfare programs in order to strengthen families' ability to manage. Recognizing that resources are limited and social protection programs are inadequately developed, it is critical to increase support to family-based and communitybased care, particularly to the poorest households, and to develop appropriate supports for children when family-based care is not possible. Further research is required to examine 
local- or government-funded institutions and those that are not faith based. More in-depth research is also recommended to examine which models of care (Embleton et al. 2014) have better outcomes and are more suitable to provide alternative care in the Kenyan context. Whether and how kinship is produced in alternative care systems should also be a priority in future policies and guidelines on alternative care in low-income settings.

Funding This study was funded by Eunice Kennedy Shriver National Institute of Child Health and Human Development (Grant No. R01HD060478).

\section{Compliance with Ethical Standards}

Conflict of interest The authors declare that they have no conflict of interest.

Ethical Approval All procedures performed in studies involving human participants were in accordance with the ethical standards of the institutional and/or national research committee and with the 1964 Helsinki declaration and its later amendments or comparable ethical standards.

Informed Consent Informed consent was obtained from all individual participants included in the study.

Open Access This article is distributed under the terms of the Creative Commons Attribution 4.0 International License (http://creativecommons.org/licenses/by/4.0/), which permits unrestricted use, distribution, and reproduction in any medium, provided you give appropriate credit to the original author(s) and the source, provide a link to the Creative Commons license, and indicate if changes were made.

\section{References}

Abebe, T. (2009). Orphanhood, poverty and the care dilemma: Review of global policy trends. Social Work \& Society, 7(1), 9-11.

Atwoli, L., Ayuku, D. O., Hogan, J., Koech, J., Vreeman, R. C., Ayaya, S. O., et al. (2014). Impact of domestic care environment on trauma and posttraumatic stress disorder among orphans in Western Kenya. PLoS ONE, 9(3), 1-7. https://doi.org/10.1371/journal.pone.0089937.

Ayuku, D. O., Embleton, L., Koech, J., Atwoli, L., Hu, L., Ayaya, S. O., et al. (2014). The government of Kenya cash transfer for orphaned and vulnerable children: Cross-sectional comparison of household and individual characteristics of those with and without. BMC International Health and Human Rights, 14(1), 25. https://doi.org/10.1186/1472-698X-14-25.

Berens, A. E., \& Nelson, C. A. (2015). The science of early adversity: Is there a role for large institutions in the care of vulnerable children? The Lancet, 386(9991), 388-398. https://doi.org/10.1016/S0140 $-6736(14) 61131-4$.

Bosworth, J., Alviar, C., Corral, L., Davis, B., Musembi, D., Mwasiaji, W., et al. (2016). The cash transfer programme for orphans and vulnerable children: The catalyst for cash transfers in Kenya. In B. Davis, S. Handa, N. Hypher, N. W. Rossi, P. Winters, \& J. Yablonski (Eds.), From evidence to action. The story of cash transfers and impact evaluation in Sub-Saharan Africa (Vol. 19, p. 404). Oxford: Oxford University Press. https://doi.org/10.1080/00220388.2016.1222679.

Braitstein, P. (2015). Institutional care of children in low- and middle-income settings: Challenging the conventional wisdom of Oliver Twist. Global Health: Science and Practice, 3(3), 330-332. https://doi. org/10.9745/GHSP-D-15-00228.

Braitstein, P., Ayaya, S. O., Ayuku, D. O., Delong, A., \& Atwoli, L. (2017). Child abuse and neglect in Charitable Children's Institutions in Uasin Gishu County, Kenya: A challenge of context. In A. Rus, S. Parris, \& E. Stativa (Eds.), Child maltreatment in residential care. Cham: Springer. https://doi. org/10.1007/978-3-319-57990-0_16.

Braitstein, P., Ayaya, S. O., Nyandiko, W. M., Kamanda, A., Koech, J., Gisore, P., et al. (2013). Nutritional status of orphaned and separated children and adolescents living in community and institutional 
environments in Uasin Gishu County, Kenya. PLoS ONE, 8(7), e70054. https://doi.org/10.1371/journ al.pone.0070054.

Bratton, M., \& Kimenyi, M. S. (2008). Voting in Kenya: Putting ethnicity in perspective. Journal of Eastern African Studies, 2(2), 272-289. https://doi.org/10.1080/17531050802058401.

Braun, V., \& Clarke, V. (2006). Using thematic analysis in psychology. Qualitative Research in Psychology, 3(2), 77-101. https://doi.org/10.1191/1478088706qp063oa.

Bryant, J. H. (2009). Kenya's cash transfer program: Protecting the health and human rights of orphans and vulnerable children. Health and Human Rights, 11(2), 65-76.

Case, A., Paxson, C., \& Ableidinger, J. (2004). Orphans in Africa: Poverty and school enrollment. Demography, 41(3), 483-508. https://doi.org/10.1353/dem.2004.0019.

Cheney, K. E. (2017). Crying for our elders: African orphanhood in the age of HIV and AIDS. Chicago: The University of Chicago Press.

Cheney, K. E., \& Rotabi, K. S. (2014). Addicted to orphans: How the global orphan industrial complex jeopardizes local child protection systems. In C. Harker, K. Hörschelmann, \& T. Skelton (Eds.), Conflict, violence and peace. Geographies of children and young people (pp. 89-107). Singapore: Springer. https://doi.org/10.1007/978-981-287-038-4_3.

Chijere Chirwa, W. (2002). Social exclusion and inclusion: Challenges to orphan care in Malawi. Nordic Journal of African Studies, 11(1), 93-113. https://doi.org/10.1017/CBO9781107415324.004.

Coffey, A., \& Atkinson, P. (1996). Concepts and coding. Making sense of qualitative data: Complementary research strategies (pp. 26-53). Thousand Oaks, CA: Sage Publications.

Cooper, E. (2012). Following the law, but losing the spirit of child protection in Kenya. Development Practice, 22(4), 486-497. https://doi.org/10.1080/09614524.2012.673554.

Creswell, J. W. (2007). Qualitative inquiry and research design: Choosing among five traditions (2nd ed.). Thousand Oaks, CA: Sage Publications.

Department of Children's Services, Ministry of Gender, Children and Social Development, \& UNICEF Kenya. (2008). A technical assessment of the legal provisions and practices of guardianship, foster care and adoption of children in Kenya. Retrieved November 7, 2017 from https://resourcecentre.savet hechildren.net/sites/default/files/documents/6399.pdf.

Drah, B. (2012). Orphans in sub-Saharan Africa: The crisis, the interventions, and the anthropologist. Africa Today, 59(2), 2-21. https://doi.org/10.2979/africatoday.59.2.3.

Drimie, S. (2003). HIV/AIDS and land: Case studies from Kenya, Lesotho and South Africa. Development Southern Africa, 20(5), 647-658. https://doi.org/10.1080/0376835032000149289.

Dunn, A., Jareg, E., \& Webb, D. (2007). A last resort: The growing concern about children in residential care. London. Retrieved August 28, 2018 from https://resourcecentre.savethechildren.net/node/2644/ pdf/2644.pdf.

Elias, B., Mignone, J., Hall, M., Hong, S. P., Hart, L., \& Sareen, J. (2012). Trauma and suicide behaviour histories among a Canadian indigenous population: An empirical exploration of the potential role of Canada's residential school system. Social Science and Medicine, 74(10), 1560-1569. https://doi. org/10.1016/j.socscimed.2012.01.026.

Embleton, L., Ayuku, D. O., Kamanda, A., Atwoli, L., Ayaya, S. O., Vreeman, R., et al. (2014). Models of care for orphaned and separated children and upholding children's rights: Cross-sectional evidence from western Kenya. BMC International Health and Human Rights, 14(1), 9. https://doi. org/10.1186/1472-698X-14-9.

Embleton, L., Lee, H., Gunn, J., Ayuku, D. O., \& Braitstein, P. (2016). Causes of Child and youth homelessness in developed and developing countries. JAMA Pediatrics, 170(5), 435. https://doi.org/10.1001/ jamapediatrics.2016.0156.

Embleton, L., Nyandat, J., Ayuku, D. O., Sang, E., Kamanda, A., Ayaya, S. O., et al. (2017). Sexual behavior among orphaned adolescents in western Kenya: A comparison of institutional- and family-based care settings. Journal of Adolescent Health, 60(4), 417-424. https://doi.org/10.1016/j.jadohealth .2016.11.015.

Farber, B. (1962). Types of family organization: Child-oriented, home-oriented, and parent oriented. Human behaviour and social processes: An interactionist approach (pp. 285-306). Oxon: Routledge.

Foster, G. (2000). The capacity of the extended family safety net for orphans in Africa. Psychology, Health and Medicine, 5(1), 55-62. https://doi.org/10.1080/135485000106007.

Freeman, M., \& Nkomo, N. (2006). Guardianship of orphans and vulnerable children. A survey of current and prospective South African caregivers. AIDS Care: Psychological and Socio-Medical Aspects of AIDS/HIV, 18(4), 302-310. https://doi.org/10.1080/09540120500359009.

Ghera, M. M., Marshall, P. J., Fox, N. A., Zeanah, C. H., Nelson, C. A., Smyke, A. T., et al. (2009). The effects of foster care intervention on socially deprived institutionalized children's attention and positive 
affect: Results from the BEIP study. Journal of Child Psychology and Psychiatry and Allied Disciplines, 50(3), 246-253. https://doi.org/10.1111/j.1469-7610.2008.01954.x.

Government of Kenya, UNICEF, \& Global Affairs Canada. (2015). Taking child protection to the next level in Kenya. Retrieved August 17, 2018 from https://www.unicef.org/protection/files/Kenya_CP_syste m_case_study.pdf.

Green, J., \& Thorogood, N. (2009). Qualitative methods for health research (2nd ed.). Thousand Oaks, CA: Sage Publications.

Hollingsworth, L. D. (1999). American families, and the transracial adoption controversy. Social Work, 44(5), 443-453. https://doi.org/10.1093/sw/44.5.443.

Humphreys, K. L., Gleason, M. M., Drury, S. S., Miron, D., Nelson, C. A., Fox, N. A., et al. (2015). Effects of institutional rearing and foster care on psychopathology at age 12 years in Romania: Follow-up of an open, randomised controlled trial. The Lancet Psychiatry, 2(7), 625-634. https://doi.org/10.1016/ S2215-0366(15)00095-4.

Huynh, H. V. (2014). New directions in orphan and vulnerable children policy and research: A focus on supporting "suitable" institutions when placement is "necessary" for a child. American Journal of Orthopsychiatry, 84(4), 387-394. https://doi.org/10.1037/h0099847.

Kabiru, D. (2018, January 25). Children's home faces closure over sexual abuse allegations. Citizen digital. Retrieved September 10, 2018 from https://citizentv.co.ke/news/childrens-home-faces-closure-oversexual-abuse-allegations-189249/.

Kamanda, A., Embleton, L., Ayuku, D. O., Atwoli, L., Gisore, P., Ayaya, S. O., et al. (2013). Harnessing the power of the grassroots to conduct public health research in sub-Saharan Africa: A case study from western Kenya in the adaptation of community-based participatory research (CBPR) approaches. $B M C$ Public Health, 13(1), 91. https://doi.org/10.1186/1471-2458-13-91.

Kenya National Bureau of Statistics, \& Ministry of Planning and National Development. (2018). Basic report on well-being in Kenya. Retrieved September 4, 2018 from https://www.knbs.or.ke/download/ basic-report-well-kenya-based-201516-kenya-integrated-household-budget-survey-kihbs/.

King, M., Smith, A., \& Gracey, M. (2009). Indigenous health part 2: The underlying causes of the health gap. The Lancet, 374(9683), 76-85. https://doi.org/10.1016/S0140-6736(09)60827-8.

Kitto, S. C., Chesters, J., \& Grbich, C. (2001). Quality in qualitative research: Criteria for authors and assessors in the submission and assessment of qualitative research articles for the Medical Journal of Australia. Medical Journal of Australia, 188(4), 243-246.

Kyomugisha, F., \& Rutayuga, J. B. K. (2011). Extended family and kinship network systems for caring for children. In O.-M. Aborampah \& N. Sudarkasa (Eds.), Extended families in Africa and the African diaspora (pp. 183-199). Trenton: African World Press.

LaRossa, R., \& Reitzes, D. C. (1993). Symbolic interactionism and family studies. In P. Boss, W. J. Doherty, R. LaRossa, W. R. Schumm, \& S. K. Steinmetz (Eds.), Sourcebook of family theories and methods: A contextual approach (pp. 155-179). Boston, MA: Springer. https://doi.org/10.1007/978-0-387-85764 -0 .

Madhavan, S. (2004). Fosterage patterns in the age of AIDS: Continuity and change. Social Science and Medicine, 58(7), 1443-1454. https://doi.org/10.1016/S0277-9536(03)00341-1.

McPherson, D. (2006). Property grabbing and Africa's orphaned generation: A legal analysis of the implications of the HIV/AIDS pandemic for inheritance by orphaned children in Uganda, Kenya, Zambia and Malawi. Retrieved September 8, 2018 from https://www.law.utoronto.ca/documents/ihrp/HIV_ mcpherson.doc.

Miller, B. S., Spratt, E. G., Himes, J. H., Condon, D., Summer, A., Papa, C. E., et al. (2015). Growth failure associated with early neglect: Pilot comparison of neglected US children and international adoptees. Journal of Pediatric Endocrinology and Metabolism, 28(1-2), 111-115. https://doi.org/10.1515/ jpem-2014-0231.

Milligan, I., Withington, R., Connelly, G., \& Gale, C. (2016). Alternative child care and deinstitutionalisation in sub-Saharan Africa. Retrieved August 7, 2018 from https://pure.strath.ac.uk/portal/files/66699 664/Milligan_etal_2016_Alternative_child_care_and_deinstitutionalisation_in_sub_saharan_afric a.pdf.

Mishra, V., \& Bignami-Van Assche, S. (2008). Orphans and vulnerable children in high HIV-prevalence countries in sub-Saharan Africa. DHS analytical studies, 15(September). Retrieved September 4, 2018 from http://dhsprogram.com/pubs/pdf/AS15/AS15.pdf.

Monasch, R., \& Boerma, J. T. (2004). Orphan hood and childcare patterns in sub-Saharan Africa: An analysis of national surveys from 40 countries. AIDS, 18(Suppl 2), S55-S65. https://doi.org/10.1097/01. aids.0000125989.86904.fe.

Morantz, G., Cole, D. C., Ayaya, S. O., Ayuku, D. O., \& Braitstein, P. (2013). Maltreatment experiences and associated factors prior to admission to residential care: A sample of institutionalized children and 
youth in western Kenya. Child Abuse and Neglect, 37(10), 778-787. https://doi.org/10.1016/j.chiab u.2012.10.007.

Morantz, G., \& Heymann, J. (2010). Life in institutional care: The voices of children in a residential facility in Botswana. AIDS Care: Psychological and Socio-Medical Aspects of AIDS/HIV, 22(1), 10-16. https ://doi.org/10.1080/09540120903012601.

Mulheir, G., Daphne Programme, World Health Organization, \& University of Birmingham. (2007). Deinstitutionalising and transforming children's services: A guide to good practice. Birmingham: University of Birmingham.

Ndanyi, M. (2018). 40 Uasin Gishu children's homes to be inspected over illegal operations. The star. Retrieved September 10, 2018 from https:/www.the-star.co.ke/news/2016/04/23/40-uasin-gishu-child rens-homes-to-be-inspected-over-illegal-operations_c1337777.

Neimetz, C. (2011). Navigating family roles within an institutional framework: An exploratory study in one private Chinese orphanage. Journal of Child and Family Studies, 20(5), 585-595. https://doi. org/10.1007/s10826-010-9431-2.

Patton, M. Q. (2002). Qualitative evaluation and research methods. Beverly Hills, CA: Sage. https://doi. org/10.1002/nur.4770140111.

PEPFAR. (2017). Children. PEPFAR fact sheet. Retrieved September 2, 2018 from https://www.pepfar.gov/ documents/organization/264886.pdf.

Petrowski, N., Cappa, C., \& Gross, P. (2017). Estimating the number of children in formal alternative care: Challenges and results. Child Abuse and Neglect, 70, 388-398. https://doi.org/10.1016/j.chiab u.2016.11.026.

Pinheiro, P. S. (2006). World report on violence against children. Retrieved August 4, 2018 from https:// www.unicef.org/violencestudy/I.WorldReportonViolenceagainstChildren.pdf.

Plummer, C. A., \& Njuguna, W. (2009). Cultural protective and risk factors: Professional perspectives about child sexual abuse in Kenya. Child Abuse and Neglect, 33(8), 524-532. https://doi.org/10.1016/j.chiab u.2009.02.005.

Powell, G., Chinake, T., Mudzinge, D., Maambira, W., \& Mukutiri, S. (2004). Children in residential care: The Zimbabwean experience. Retrieved August 28, 2018 from https://bettercarenetwork.org/sites/ default/files/attachments/ChildreninResidentalCare-TheZimbabweanExperience.pdf.

Prasad, P. (2005). Symbolic interactionism: Searching for self and meaning. In Crafting qualitative research: Working in the postpositivist tradition (p. 340). London: Routledge.

Pryce, J. M., Jones, S. L., Wildman, A., Thomas, A., Okrzesik, K., \& Kaufka-Walts, K. (2016). Aging out of care in Ethiopia: Challenges and implications facing orphans and vulnerable youth. Emerging Adulthood, 4(2), 119-130. https://doi.org/10.1177/2167696815599095.

Redazione. (2017). Stop new Children Charitable Institutions in Kenya: No more registration by the government to orphanages. Retrieved September 10, 2018 from http://www.malindikenya.net/en/articles/ social/solidarity/stop-new-children-charitable-istitutions-in-kenya.html.

Republic of Kenya, \& National Council for Children's Services (NCCS). (2015). National plan of action for children in Kenya 2015-2022. Retrieved August 7, 2018 from http://www.childrenscouncil.go.ke/ images/documents/Policy_Documents/National-Plan-of-Action-for-Children-in-Kenya-2015.pdf.

Roby, J. L. (2011). Children in informal alternative care. Discussion paper. New York: UNICEF, Child Protection Section. Retrieved September 2, 2018 from https://www.unicef.org/protection/Informal_care_ discussion_paper_final.pdf.

Roeber, E., \& Kenya Network of Careleavers (KNCL). (2011). A fair chance to life: Young careleavers in Kenya. Retrieved August 4, 2018 from https://bettercarenetwork.org/library/principles-of-good-carepractices/leaving-alternative-care-and-reintegration/a-fair-chance-to-life-young-careleavers-in-kenya.

Rotabi, K. S., Roby, J. L., \& McCreery Bunkers, K. (2017). Altruistic exploitation: Orphan tourism and global social work. British Journal of Social Work, 47(3), 648-665. https://doi.org/10.1093/bjsw/ bcv147.

Ryan, G. W., \& Bernard, H. R. (2003). Techniques to identify themes. Field Methods, 15(1), 85-109. https:// doi.org/10.1177/1525822X02239569.

Sherr, L., Roberts, K. J., \& Gandhi, N. (2017). Child violence experiences in institutionalised/orphanage care. Psychology, Health and Medicine, 22, 31-57. https://doi.org/10.1080/13548506.2016.1271951.

Smyke, A. T., Koga, S. F., Johnson, D. E., Fox, N. A., Marshall, P. J., Nelson, C. A., et al. (2007). The caregiving context in institution-reared and family-reared infants and toddlers in Romania. Journal of Child Psychology and Psychiatry and Allied Disciplines, 48(2), 210-218. https://doi.org/10.111 1/j.1469-7610.2006.01694.x.

Stryker, S. (1968). Identity salience and role performance: The relevance of symbolic interaction theory for family research author(s): Sheldon Stryker source. Journal of Marriage and Family, 30(4), 558-564. 
The Kenya CT-OVC Evaluation Team. (2012). The impact of Kenya's cash transfer for orphans and vulnerable children on human capital. Journal of Development Effectiveness, 4(1), 38-49. https://doi. org/10.1080/19439342.2011.653578.

The National Council for Children's Services. (2015). National directory for children's service providers. Nairobi, KE. Retrieved August 27, 2018 from https://bettercarenetwork.org/library/social-welfare-syste $\mathrm{ms} /$ data-and-monitoring-tools/kenya-national-directory-for-children's-service-providers.

Ucembe, S. (2016). Institutional care for children in Kenya. In T. Islam \& L. Fulcher (Eds.), Residential child and youth care in a developing world: Global perspectives 1 (pp. 186-200). Cape Town, ZA: The CYC-Net Press.

Umbima, K. J. (1991). Regulating foster care services: The Kenyan situation. Child Welfare, 70(2), $169-174$.

UNICEF. (2017). Orphans. Retrieved January 22, 2018 from https://www.unicef.org/media/media_45279 .html.

UNICEF Kenya, \& National Council for Children's Services. (2014). Situation analysis of children and adolescents in Kenya: Our children, our future. Retrieved November 7, 2017 from https://www.unicef.org/ kenya/SITAN_2014_Web.pdf.

UNICEF, \& Republic of Kenya. (2013). National standards for best practices in Charitable Children's Instituitions. Retrieved August 14, 2018 from https://bettercarenetwork.org/sites/default/files/Natio nalStandardsforBestPracticesinCharitableChildren\%27sInstitutions.pdf.

UNICEF, \& Republic of Kenya. (2014). Guidelines for the alternative family care of children in Kenya. Retrieved August 4, 2018 from https://bettercarenetwork.org/sites/default/files/GuidelinesfortheAlte rnativeFamilyCareofChildreninKenya.pdf.

van den Dries, L., Juffer, F., van Ijzendoorn, M. H., \& Bakermans-Kranenburg, M. J. (2009). Fostering security? A meta-analysis of attachment in adopted children. Children and Youth Services Review, 31(3), 410-421. https://doi.org/10.1016/j.childyouth.2008.09.008.

van Ijzendoorn, M. H., Luijk, M. P. C. M., \& Juffer, F. (2008). IQ of children growing up in children's homes: A meta-analysis on IQ delays in orphanages. Merrill-Palmer Quarterly, 54(3), 341-366. https ://doi.org/10.1353/mpq.0.0002.

Wanat, S., Whisnant, J., Reicherter, D., Solvason, B., Juul, S., Penrose, B., et al. (2010). Coping with the challenges of living in an Indonesian residential institution. Health Policy, 96(1), 45-50. https://doi. org/10.1016/j.healthpol.2010.01.001.

Whetten, K., Ostermann, J., Pence, B. W., Whetten, R. A., Messer, L. C., Ariely, S., et al. (2014). Threeyear change in the wellbeing of orphaned and separated children in institutional and family-based care settings in five low- and middle-income countries. PLoS ONE, 9(8), e104872. https://doi.org/10.1371/ journal.pone.0104872.

Whetten, K., Ostermann, J., Whetten, R. A., Pence, B. W., O’Donnell, K., Messer, L. C., et al. (2009). A comparison of the wellbeing of orphans and abandoned children ages 6-12 in institutional and community-based care settings in 5 less wealthy nations. PLOS ONE, 4(12), e8169. https://doi.org/10.1371/ journal.pone.0008169.

Williamson, J., \& Greenberg, A. (2010, September). Families, not orphanages. Better care network working paper. Retrieved August 19, 2018 from https://bettercarenetwork.org/library/particular-threats-to-child rens-care-and-protection/effects-of-institutional-care/families-not-orphanages.

Publisher's Note Springer Nature remains neutral with regard to jurisdictional claims in published maps and institutional affiliations.

\section{Affiliations}

\section{Allison Gayapersad ${ }^{4}$. Caroline Ombok ${ }^{3}$ - Allan Kamanda ${ }^{6} \cdot$ Carren Tarus $^{3}$. David Ayuku ${ }^{5}$ Paula Braitstein ${ }^{1,2,3}$}

1 Division of Epidemiology, Dalla Lana School of Public Health, University of Toronto, Health Sciences Building, 6th Floor, 155 College Street, Toronto, ON M5T 3M7, Canada

2 Department of Medicine, School of Medicine, College of Health Sciences, Moi University, Eldoret, Kenya 
3 The Academic Model Providing Access to Healthcare (AMPATH), Eldoret, Kenya

4 Department Social and Behavioural Health Sciences, Dalla Lana School of Public Health, University of Toronto, Toronto, Canada

5 Department of Behavioral Sciences, School of Medicine, College of Health Sciences, Moi University, Eldoret, Kenya

6 Moi Teaching and Referral Hospital, Eldoret, Kenya 